\title{
COMMERCIAL APPLICATION OF GIBBERELLIC ACID TO HOPS
}

\author{
By A. S. NASH and P. D. MULLANEY \\ Carlton and United Breweries, Melbourne
}

T HE effect of gibberellic acid as a growth-promoting substance caused attention to be focused upon it, when a great disadvantage of newly bred triploid hop plants became apparent. The triploid material, being partly sterile, tended to hang in the burr stage for a long period, and it was considered that gibberellic acid could perhaps force the triploids from the burr stage, besides giving an economic increase in yield.

To implement such a hypothesis, preliminary applications of gibberellic acid were carried out to determine the optimal time of application. For these determinations, the potassium salt of gibberellic acid under the trade name 'Gibrel' was used. Laterals at different stages of burr development on different plants of the triploid material, known as 12/5/28, were completely covered in a plastic bag and sprayed by a Rega continuous-spray unit with the 'Gibrel' solution of concentration 50 parts per million. These preliminary sprays showed that the time of applica. tion could reasonably be narrowed down to when the stigmas of the fernale flowers were $\frac{1}{8}$ in. or greater in length. Earlier application of the spray resulted in excessive elongation of the sub-laterals (this was of the order of 100 per cent in comparison with the control laterals) and later application showed a decrease in overall effect.

Once the time of application had been suitably determined, a further trial with different strengths of application was attempted. Concentrations of $50,25,12 \cdot 5,6 \cdot 25$ and $0 \cdot 625$ parts per million (p.p.m.) respectively were used, with applications carried out exactly as above on laterals of different plants with individual cone weights for each treatment being recorded. These were compared to the cone weights from similar laterals from unsprayed vines used as controls. The gibberellic acid-sprayed material showed typical reactions'. 'The leaves became paler within 4 days ; this, however, was only temporary and after a further 6 days the leaves had regained their normal colour. The sprayed material showed normal development of the cones, with no abnormal growth of the sub-laterals, and was approximately 10 days in advance in maturity on the unsprayed control material. Not only was the maturity of the cones pushed forward, but also the cones along the sprayed laterals were more even in development, so that the harvest time became more critical, with practically all cones at the same stage of maturity at the same time. However, those cones developed from gibberellic acid-sprayed burr were more subject to wind burn than the controls and the degree of burn was approximately the same for all concentrations. The most significant part of the growth of the gibberellic acid material was the great initial surge of development, which although slowing down with time, was still sufficient to ripen the cones 10 days before the control cones. The actual cone weights are set out in Table 1.

It was decided that the concentration of gibberellic acid at 12.5 p.p.m. would give the desired effect of increase in yield and decrease in maturity time,

\begin{tabular}{|c|c|c|}
\multicolumn{2}{c}{ Table 1 } \\
\hline \begin{tabular}{c|c} 
Concentration of spray \\
(p.p.m.)
\end{tabular} & $\begin{array}{c}\text { No. of cones } \\
\text { in treatment }\end{array}$ & $\begin{array}{c}\text { Weight/cone } \\
\text { (gm.) }\end{array}$ \\
\hline 0.625 & 164 & 0.82 \\
6.25 & 212 & 0.85 \\
12.5 & 225 & 1.10 \\
25.0 & 148 & 1.40 \\
50.0 & 151 & 1.44 \\
Control & 594 & 0.77 \\
\hline
\end{tabular}

without being too expensive for an equitable return.

Since most commercial growers of hops are equipped with overhead sprays, a full plant trial was adopted whereby the gibberellic acid applied at 12.5 p.p.m. would be sprayed from above the plant by means of a fine nozzle shower-head. The variety used was a locally bred, high analysis hop called Pride of Ringwood. The shower-head was connected to a carbon dioxide cylinder with an apparent head pressure of $30 \mathrm{lb} . / \mathrm{sq}$. in., but due to the friction loss along the long, small diameter hose necessary to reach the tall crop, the actual spray was delivered at somewhat less than $30 \mathrm{lb} . / \mathrm{sq}$. in.; however, excellent coverage of the plants was effected due to the fine spray achieved. The time of application was allowed to progress a little past the optimal time to make sure that most of the burr was at a receptive stage. The average yield per sprayed hill was $7 \cdot 25 \mathrm{lb}$. while the average yield for the control hills was $5 \cdot 20 \mathrm{lb}$. This gave an average increase of $2.05 \mathrm{lb}$./hill-a large increase when considered in terms of 850 hills/acre. On yield results alone, the application of gibberellic acid seemed justifiable, since the yields were increased and the decreased time of maturity would allow for a less restrictive harvest period. The main interest in bought hops is the percentage of $\alpha$ resin in the purchased product. The two lots of material, treated with gibberellic acid and controls, were analysed for $\alpha$-resin content by the Verzele rapid polarimetric method ${ }^{2}$, and further tests for total soft resin content were carried out by the WalkerHastings method ${ }^{3}$.

\begin{tabular}{|c|c|c|}
\hline & $\begin{array}{c}a \cdot \text { Resin } \\
\text { (per cent) }\end{array}$ & $\begin{array}{l}\text { Total soft resin } \\
\text { (per cent) }\end{array}$ \\
\hline $\begin{array}{l}\text { Treated hops } \\
\text { Untreated hops }\end{array}$ & $\begin{array}{c}1 \cdot 8 \\
10 \cdot 16\end{array}$ & $\begin{array}{r}9 \cdot 7 \\
21 \cdot 8\end{array}$ \\
\hline
\end{tabular}

Table 2 shows that the most important substance in the hops from the brewer's point of view has been greatly decreased by application of gibberellic acid. Further work on estimation of oils by gas chromatography was carried out and appears to indicate that here again there is a difference in percentages of the various oil components between gibberellic acidtreated and normal hops; however, this work is inconclusive and requires verification.

'Brian, P. W., and Grove, J. F., Endeavour (July 1957).

${ }^{2}$ Wallenstein Lab. Comm. No. 68, 20, 7 (1957).

${ }^{3}$ J. Inst. Brew., 39, 509 (1933). 